\title{
Association between Mobile Phone Addiction Index and Sugar-Sweetened Food Intake in Medical College Students Stratified by Sex from Shanghai, China
}

\author{
Shaojie Liu ${ }^{1,+}$, Weiqiang Zhou ${ }^{2,+}$, Jiangqi Wang ${ }^{1}$, Bo Chen ${ }^{1} \oplus$, Gengsheng $\mathrm{He}^{1}$ and Yingnan Jia ${ }^{1, *}$ \\ 1 School of Public Health, Key Lab of Public Health Safety of the Ministry of Education, Fudan University, \\ Shanghai 200032, China; liushaojie@fudan.edu.cn (S.L.); 18211020091@fudan.edu.cn (J.W.); \\ chenb@fudan.edu.cn (B.C.); gshe@shmu.edu.cn (G.H.) \\ 2 Informatization Office, Fudan University, Shanghai 200032, China; wqzhou@fudan.edu.cn \\ * Correspondence: jyn@fudan.edu.cn \\ + These authors contributed equally to this work.
}

Citation: Liu, S.; Zhou, W.; Wang, J.; Chen, B.; He, G.; Jia, Y. Association between Mobile Phone Addiction Index and Sugar-Sweetened Food Intake in Medical College Students Stratified by Sex from Shanghai, China. Nutrients 2021, 13, 2256. https://doi.org/10.3390/nu13072256

Academic Editor: Rosa Casas

Received: 25 May 2021

Accepted: 29 June 2021

Published: 30 June 2021

Publisher's Note: MDPI stays neutral with regard to jurisdictional claims in published maps and institutional affiliations.

Copyright: () 2021 by the authors. Licensee MDPI, Basel, Switzerland. This article is an open access article distributed under the terms and conditions of the Creative Commons Attribution (CC BY) license (https:// creativecommons.org/licenses/by/ $4.0 /)$.

\begin{abstract}
This study's objective was to depict sugar-sweetened food (SSF) consumption in medical college students stratified by sex from Shanghai, China, and to explore the association between the Mobile Phone Addiction Index (MPAI) and SSF intake. The data were obtained from 1121 medical college students from the Fudan University, Shanghai, China, who took an online questionnaire investigation in December 2020. Data included demographics, the MPAI, the Nutrition Literacy Assessment Questionnaire (NLAQ), total and food expenditure per month, the International Physical Activity Questionnaire (IPAQ), and a food frequency questionnaire (carbonated beverages (CB), other sugar-based beverages (OSBB), sugar/chocolate). We evaluated the association between the MPAI and three types of SSF intake according to multivariate logistic regression analysis stratified by sex. The mean CB, OSBB, and sugar/chocolate intakes were, respectively, $65.66 \mathrm{~mL} / \mathrm{d}, 74.20 \mathrm{~mL} / \mathrm{d}$, and $4.96 \mathrm{~g} / \mathrm{d}$ in men and $30.42 \mathrm{~mL} / \mathrm{d}, 71.48 \mathrm{~mL} / \mathrm{d}$, and $4.99 \mathrm{~g} / \mathrm{d}$ in women. The MPAI was positively associated with SSF intake, regardless of sex. In men, the CB and OSBB odds ratios (ORs) were, respectively, 1.023 (95\% CI: 1.004-1.042), 1.019 (95\% CI: 1.001-1.038); and in women, the CB, OSBB, and sugar/chocolate ORs were, respectively, 1.026 (95\% CI: 1.013-1.039), 1.020 (95\% CI: 1.007-1.033), and 1.019 (95\% CI: 1.006-1.032). Age, NLAQ, total expenditure, food expenditure, and total physical activity also were related to SSF intake. Age and the application capacity of the NLAQ were negatively associated with SSF intake, whereas comprehension capacity of the NLAQ, total and food expenditure, and total physical activity were positively associated with SSF intake. This study confirmed that SSF intake is widespread among medical college students from Shanghai, China, even if they have relatively high nutrition health literacy. From a public health perspective, it is necessary to reduce SSF intake in medical college students by decreasing the MPAI, controlling the total and food expenditure per month in high-consumption areas, and improving the application ability of the NLAQ. Further studies are needed to explore the MPAI and other potential factors that may influence SSF intake of college students by expanding the sample size of college students throughout China, and the causal association between them.
\end{abstract}

Keywords: sugar-sweetened food; mobile phone addiction; medical college students

\section{Introduction}

Sugar-sweetened food (SSF) includes sugar-sweetened beverages (carbonated or noncarbonated beverages, soft drinks, sport drinks, fruit drinks, and milk tea) and foods (sugar, sweetened chocolate, and pastries), which have become the main daily source of added sugar around the world [1,2]. A growing body of literature documents the prevalence of SSF intake in children, adolescents, and adults, likely caused by the high content of added sugars, especially sucrose or fructose, which induce strong positive hedonic stimulation of 
the sweetness quality sensors [3]. The World Health Organization (WHO) recommends reducing the energy provided by free sugar in SSF to less than $5 \%$ of the daily energy intake for optimal health benefit [4]. Recent literature on this topic has indicated that SSF intake in children, adolescents, and adults exceeds the intake recommended by the WHO. In the United States, a survey showed that nearly $64 \%$ of young people, aged 2-19 years, drink sugar-sweetened beverages every day [5], which contributes to $8.4 \%$ of their total daily energy intake. Studies conducted by Brand-Miller and Aburto showed that sugar-sweetened beverage intake contributes to $5.5 \%$ and $8.3 \%$ of the total energy intake in children from Australia and Mexico, respectively [6,7]. An increasing trend in sugar-sweetened beverage intake, equivalent to $6.5 \%$ of the total daily energy intake, was also observed among adults in the United States [8,9]. Overconsumption of SSF has been shown to induce uncontrolled liver uptake of fructose, which leads to hepatic lipid accumulation and dyslipidemia, reduces insulin sensitivity, and elevates uric acid levels [10]. This dysregulation is related to a series of diseases, including weight gain and obesity [11], metabolic syndrome [12], type 2 diabetes [13], cardiovascular disease [14], fatty liver [15], and hyperuricemia [16].

Previous research established a critical role for screen time, including television viewing, in children's SSF intake [17]. Prolonged television viewing time was positively associated with sugar intake [18]. With the advent of the Internet era, however, the usage of mobile phones has surpassed that of viewing television [19]. Few studies have suggested that the increase in mobile phone usage is linked to increased intake of SSF [20]. Yet, the amount of time spent using mobile phones alone does not fully reflect the physical, psychological, and behavioral characteristics of mobile phone users. The Mobile Phone Addiction Index (MPAI), developed by Leung [21] to characterize mobile phone addiction symptoms and provide a comprehensive assessment of addiction level, has been widely applied in various studies around the world [22,23]. This methodology, consisting of a 17-item MPAI scale, was used to categorize the four mobile phone addiction symptoms, including "inability to control craving", "feeling anxious and lost", "withdrawal/escape", and "productivity loss". To the best of our knowledge, until our present study, no research applied this methodology to explore the relationship between the MPAI and SSF intake.

In addition to MPAI, other potential factors also influence the intake of SSF from several studies: Zoellner et al. discovered health literacy-focused strategies were an effective way to decrease the sugar-sweetened beverage intake [24]; Chen et al. found an association between living expenditure and sugar-sweetened beverage intake [25]; Santaliestra-Pasias et al. found that physical activity was related to SSF intake [26]. These factors influencing SSF intake were also included in our research. Meanwhile, a lot of discussions have focused on SSF intake in children and adolescents. Compared with children or adolescents, college students, with their increasing independence and autonomy, face continuous challenges in choosing food [27]. Therefore, they are more likely to consume SSF than other age groups, although this problem has received scant attention in research.

Importantly, a U.S. study revealed that among young adults, sugar-sweetened beverage intake accounts for $9.3 \%$ of the daily energy intake in men and $8.2 \%$ of the daily energy intake in women $[28,29]$. This information suggested that different factors may influence SSF intake in men and women. Thus, this issue has been considered in the design of the present study, which was conducted in the form of a cross-sectional survey performed through an online questionnaire. The purpose of this study was to depict SSF consumption and explore the association between the MPAI and SSF intake in medical college students stratified by sex from Shanghai, China. Moreover, we also examined other potential factors influencing SSF intake, including age, physical activity, total expenditure, food expenditure, Body Mass Index (BMI), and nutrition health literacy.

\section{Materials and Methods}

\subsection{Target Population}

We employed random cluster sampling in our study. First, we randomly selected four colleges and departments from the Fenglin campus of Fudan University, Shanghai, China: 
the School of Public Health, the School of Basic Medicine, the Institute of Brain Science, and the Institute of Biomedicine. All students from these colleges and departments were our target research objects, with the exception of the first-year students, who studied and lived on other campuses of Fudan University. The study was conducted in accordance with the Declaration of Helsinki, and the protocol was approved by the Ethics Committee of Medical Research, School of Public Health, Fudan University (Project identification code: IRB\#2019-01-0726S).

\subsection{Questionnaire Design}

The questionnaire was composed of different parts, including demographic information (age, sex, height, and weight), lifestyle behaviors (MPAI, Nutrition Literacy Assessment Questionnaire (NLAQ), total and food expenditure per month, International Physical Activity Questionnaire (IPAQ)), and a food frequency questionnaire (carbonated beverages (CB), other sugar-based beverages (OSBB), sugar/chocolate). Additionally, we designed two simple mathematical calculations for quality control of the questionnaire. The informed consent form was also included in the questionnaire.

\subsection{Questionnaire Survey}

We designed the survey as an online questionnaire, which was conducted anonymously to collect data of college students, in December 2020. The online questionnaire was operated by the "Wenjuanxing" platform (https:/ /www.wjx.cn/app/survey.aspx, accessed on 12 December 2020), which provides functions equivalent to those of Amazon Mechanical Turk. The online questionnaire was distributed to the target research objects. The college students who agreed to take the survey and signed the informed consent voluntarily completed the online questionnaire and allowed the use of their data for our research purpose. We collected total of 1155 questionnaires; we excluded 22 questionnaires due to calculation errors in the quality control test and 12 questionnaires for incompleteness. Finally, we retained 1121 valid questionnaires for the study, which corresponded to an effective response rate of $98.06 \%$.

\subsection{Mesurements}

\subsubsection{SSF}

Three types of SSF intake were the outcome variables in this study. We collected information on SSF intake through the food frequency questionnaire. We selected the three most representative SSFs: CB, OSBB, and sugar/chocolate. The food frequency questionnaire for each type of SSF was designed as two questions, including "How often do you consume the SSF on average?" and "How many grams or milliliters of the SSF do you consume on average?" For each SSF, the food frequency questionnaire asked two questions to estimate the intake frequency and the amount per intake. The information on intake frequency (none, less than once a month, 1-3 times a month, 1-3 times a week, 4-6 times a week, once a day, 2 times a day, 3 times a day, and above) was converted into the number of intakes per day, corresponding to the following values: $0 ; 0.02 ; 0.07 ; 0.29 ; 0.71 ; 1$; 2; and 3. Finally, the number of intakes per day and the amount per intake were used to calculate, in grams, the total daily intake of $\mathrm{CB}, \mathrm{OSBB}$, and sugar/chocolate. According to their median $(10.5 \mathrm{~mL} / \mathrm{d}, 35.0 \mathrm{~mL} / \mathrm{d}$, and $1.0 \mathrm{~g} / \mathrm{d}$, respectively), we categorized these food intakes into low or high intakes.

\subsubsection{MPAI}

MPAI was the main research factor in this study. The MPAI was developed by Leung [21] to determine the symptoms of mobile phone addiction and provide a comprehensive assessment of mobile phone addiction level. This index has been widely applied in various studies around the world [22,23]. The 17-item MPAI scale (Table S1) was used to assess four mobile phone addiction symptoms, including "inability to control craving," "feeling anxious and lost," "withdrawal/escape," and "productivity loss." We converted 
answers to questions, such as "Do your friends and family complain about your use of the mobile phone?" or "Do you feel lost without your mobile phone?" into scores, with $1=$ "not at all," 2 = "rarely," 3 = "occasionally," $4=$ "often," and $5=$ "always."

\subsubsection{Covariate Assessment NLAQ}

The NLAQ, which can reach a maximum score of 65, was developed by Wang based on the Critical Nutrition Literacy of Guttersrud [30] and the Assessment Indicators System of Health Literacy of Zhang [31]. It consists of 13 items (Table S2), which were divided into three dimensions: acquisition capacity (score ty20), including questions such as: "Do I discuss food with others?" and "Do I often refer to the information in the media?"; comprehension capacity (score ty30), including questions such as: "Do I understand the concept of 'balanced diet'?"; and application capacity (score yi15), including questions such as: "Am I willing to spend extra time or money on healthy meals?" We used the NLAQ, the reliability and validity of which has been previously demonstrated, to effectively evaluate the dietary health literacy of Chinese college students.

\section{BMI}

Height and body weight were filled out by the students themselves and were accurate to $0.1 \mathrm{~cm}$ and $0.1 \mathrm{~kg}$ in the questionnaire. The BMI $\left(\mathrm{kg} / \mathrm{m}^{2}\right)=$ weight $(\mathrm{kg}) / \mathrm{height}^{2}\left(\mathrm{~m}^{2}\right)$ was categorized into three levels based on the Working Group on Obesity in China [32]: underweight $\left(<18.5 \mathrm{~kg} / \mathrm{m}^{2}\right)$, normal weight $\left(18.5-23.9 \mathrm{~kg} / \mathrm{m}^{2}\right)$, and overweight and obese $\left(\geq 24 \mathrm{~kg} / \mathrm{m}^{2}\right)$.

\section{Total and Food Expenditure}

Total and food expenditure per month were estimated by the students in the questionnaire. We took the average living expenses from their parents and subsidies from the school every month as the total expenditure per month and took what the college students spent on food and meals as the food expenditure per month. Total and food expenditure per month were translated into dichotomous variables, based on their median (2000 and $1000 \mathrm{CNY} /$ month).

\section{Physical Activity}

The IPAQ of the questionnaire asked about three specific types of physical activity including walking; moderate-intensity activities, such as dancing, cycling, playing ping pong, and practicing tai chi; and vigorous-intensity activities, such as swimming or playing basketball and badminton. We assessed the IPAQ according to the average number of days during which they completed more than 10 min of vigorous-intensity activities, moderate-intensity activities, or walking in the past week, and recorded the duration of each type of physical activity. To help students better distinguish among the different types of physical activities, we made an example diagram for each type of physical activity. The IPAQ, which has widespread application in the international arena, can be used to measure the overall weekly physical activity of the public [33]. We used the following values to analyze each type of physical activity from the questionnaire: walking $=3.3$ metabolism equivalents $(\mathrm{MET})$; moderate-intensity activity $=4.0 \mathrm{MET}$; and vigorous-intensity activity $=8.0$ MET. The formula of IPAQ was as follows: the total physical activity $(\mathrm{MET} / \mathrm{min} / \mathrm{w})=$ the MET value of physical activity $\times$ the amount of time spent on physical activity per day $(\mathrm{min} / \mathrm{d}) \times$ the number of days of physical activity per week $(\mathrm{d} / \mathrm{w})$ [34]. We converted the continuous variables corresponding to the total physical activity into three categorical variables according to Kyu's classification, which uses cutoff values of 600 and $4000 \mathrm{MET} / \mathrm{min} / \mathrm{w}$ [35] as follows: low total physical activity $(<600 \mathrm{MET} / \mathrm{min} / \mathrm{w})$, moderate total physical activity (600-4000 MET/min/w), and high total physical activity $(\geq 4000 \mathrm{MET} / \mathrm{min} / \mathrm{w})$. 


\subsection{Statistical Analysis}

We stratified the analysis by sex. Continuous variables were described as means \pm standard deviation (SD). Categorical variables were described as frequencies (ratios). Chi-square test or t-test was employed in the equilibrium test between MPAI, age, NLAQ, BMI, total physical activity, CB, OSBB, sugar/chocolate, total expenditure, food expenditure, and sex. MPAI, age, NLAQ, BMI, total physical activity, total expenditure, and food expenditure were all used as independent variables, and three dichotomous variables (i.e., CB, OSBB, and sugar/chocolate) were used separately as dependent variables. We utilized a multivariate logistic regression model stratified by sex to examine the factors influencing SSF intake among medical college students by calculating the odds ratios (ORs) and corresponding 95\% confidence intervals (95\% CI). All statistical analyses were conducted in SAS software version 9.2 (SAS Institute Inc., Cary, NC, USA), and two-sided $p$ values $<0.05$ were considered statistically significant.

\section{Results}

Of the 1121 participants enrolled in the study, 368 (32.83\%) participants were men, with an average age of $23.22 \pm 3.32$ years, and $753(67.17 \%)$ were women, with an average age of $23.45 \pm 3.39$ years. The demographic characteristics of the participants stratified by sex are presented in Table 1 . The participants of both sexes had equal distributions of age, NLAQ, consumption of OSBB, and food expenditure per month $(p>0.05)$. The mean intakes of CB, OSBB, and sugar/chocolate were, respectively, $65.66 \mathrm{~mL} / \mathrm{d}, 74.20 \mathrm{~mL} / \mathrm{d}$, and $4.96 \mathrm{~g} / \mathrm{d}$ among male participants, and $30.42 \mathrm{~mL} / \mathrm{d}, 71.48 \mathrm{~mL} / \mathrm{d}$, and $4.99 \mathrm{~g} / \mathrm{d}$ among female participants. The mean \pm SD of MPAI score in men was $44.94 \pm 12.08$, and in women was $45.25 \pm 11.87$. There was no significant difference between the two groups $(p=0.682)$. The percentages of being overweight and obese (30.16\%), high total physical activity $(9.78 \%)$, and low total expenditure per month $(47.83 \%)$ were significantly higher in male participants than in female participants. Conversely, female participants had considerably higher percentages of being underweight $(22.05 \%)$ and had lower total physical activity $(24.97 \%)$ but had higher total expenditure per month. Regarding their SSF intake, male participants consumed higher amounts of $\mathrm{CB}$, whereas female participants had higher intake of sugar/chocolate $(p<0.05)$.

Table 2 presents the MPAI and other potential factors that may influence CB intake according to sex. After covariate adjustments, the analysis showed that the higher the MPAI, the higher the percentage of intake of CB, with an OR of 1.023 (95\% CI: 1.004-1.042) for men and an OR of 1.026 (95\% CI: 1.013-1.039) for women. In addition, in male participants, the percentage of participants with a high intake of CB increased with monthly food expenditure, resulting in an OR of 1.881 (95\% CI: 1.078-3.281).

The MPAI and other potential factors that may influence the intake of OSBB are presented in Table 3. Four variables, including MPAI, age, total expenditure, and food expenditure, significantly influenced the intake of OSBB, in both male and female participants. We found a positive association between MPAI and the intake of OSBB, with an OR of 1.019 (95\% CI: 1.001-1.038) in men and 1.020 (95\% CI: 1.007-1.033) in women. Age was negatively associated with the consumption of OSBB, with an OR of $0.929(95 \%$ CI: 0.865-0.997) in men and 0.948 (95\% CI: 0.904-0.993) in women. The total and food expenditure per month were positively associated with the intake of OSBB $(p<0.05)$.

MPAI, age, NLAQ, and total physical activity were associated with the intake of sugar/chocolate (Table 4). In female participants, the MPAI increased the odds of a high intake of sugar/chocolate (OR $=1.019,95 \%$ CI: 1.006-1.032). In addition, in women, there was a significant decrease in sugar/chocolate intake with the increase in age and application capacity of the NLAQ, with OR values of 0.948 (95\% CI: 0.906-0.993) and 0.909 (95\% CI: 0.846-0.977), respectively. In male participants, participants with higher comprehension capacity of the NLAQ and total physical activity independently had increased odds of a high intake of sugar/chocolate (OR $=1.082,95 \% \mathrm{CI}$ : $1.013-1.155)$ and $(\mathrm{OR}=2.860,95 \% \mathrm{CI}$ : 
1.047-7.812), respectively, whereas higher application capacity of the NLAQ decreased the odds of a high intake of sugar/chocolate (OR $=0.901,95 \% \mathrm{CI}$ : 0.813-0.998).

Table 1. The demographic characteristics of total 1121 participants stratified by sex.

\begin{tabular}{|c|c|c|c|}
\hline Characteristics & Male $(n=368)$ & Female $(n=753)$ & $p$ Value \\
\hline MPAI (score), Mean \pm SD & $44.94 \pm 12.08$ & $45.25 \pm 11.87$ & 0.682 \\
\hline Age (years), Mean $\pm \mathrm{SD}$ & $23.22 \pm 3.32$ & $23.45 \pm 3.39$ & 0.277 \\
\hline \multicolumn{4}{|l|}{ NLAQ (score) } \\
\hline Acquisition capacity (score), Mean \pm SD & $12.44 \pm 3.41$ & $12.27 \pm 3.37$ & 0.431 \\
\hline Comprehension capacity (score), Mean \pm SD & $21.80 \pm 4.12$ & $21.99 \pm 3.86$ & 0.471 \\
\hline Application capacity (score), Mean \pm SD & $10.81 \pm 2.64$ & $10.93 \pm 2.46$ & 0.440 \\
\hline \multicolumn{4}{|l|}{$\mathrm{BMI}\left(\mathrm{kg} / \mathrm{m}^{2}\right)$} \\
\hline Normal, $n(\%)$ & $240(65.22)$ & $541(71.85)$ & \multirow[t]{3}{*}{$<0.001$} \\
\hline Underweight, $n(\%)$ & $17(4.62)$ & $166(22.05)$ & \\
\hline Overweight and obese, $n(\%)$ & $111(30.16)$ & $46(6.11)$ & \\
\hline \multicolumn{4}{|l|}{ Total physical activity $(\mathrm{MET} / \mathrm{min} / \mathrm{w})$} \\
\hline$<600(\mathrm{MET} / \mathrm{min} / \mathrm{w}), n(\%)$ & $43(11.68)$ & $188(24.97)$ & \multirow[t]{4}{*}{$<0.001$} \\
\hline $600-4000(\mathrm{MET} / \mathrm{min} / \mathrm{w}), n(\%)$ & 289 (78.53) & $539(71.58)$ & \\
\hline$\geq 4000(\mathrm{MET} / \mathrm{min} / \mathrm{w}), n(\%)$ & $36(9.78)$ & $26(3.45)$ & \\
\hline \multicolumn{3}{|l|}{$\overline{\mathrm{C}} \mathrm{B}(\mathrm{mL} / \mathrm{d})$} & \\
\hline Low intake, $n(\%)$ & $127(34.51)$ & $434(57.64)$ & \multirow[t]{2}{*}{$<0.001$} \\
\hline High intake, $n(\%)$ & 241 (65.49) & 319 (42.36) & \\
\hline \multicolumn{4}{|l|}{$\operatorname{OSBB}(\mathrm{mL} / \mathrm{d})$} \\
\hline Low intake, $n(\%)$ & $205(55.71)$ & 399 (52.99) & \multirow[t]{2}{*}{0.391} \\
\hline High intake, $n(\%)$ & $163(44.29)$ & $354(47.01)$ & \\
\hline \multicolumn{4}{|l|}{ Sugar/chocolate (g/day) } \\
\hline Low intake, $n(\%)$ & $246(66.85)$ & 438 (58.17) & \multirow[t]{2}{*}{0.005} \\
\hline High intake, $n(\%)$ & $122(33.15)$ & 315 (41.83) & \\
\hline \multicolumn{4}{|l|}{ Total expenditure (CNY / month) } \\
\hline$<2000$ (CNY/month), $n(\%)$ & $176(47.83)$ & $274(36.39)$ & \multirow{2}{*}{$<0.001$} \\
\hline$\geq 2000(\mathrm{CNY} / \mathrm{month}), n(\%)$ & $192(52.17)$ & $479(63.61)$ & \\
\hline \multicolumn{4}{|l|}{ Food expenditure (CNY / month) } \\
\hline$<1000$ (CNY/month), $n(\%)$ & $108(29.35)$ & $249(33.07)$ & \multirow[t]{2}{*}{0.209} \\
\hline$\geq 1000$ (CNY/month), $n(\%)$ & $260(70.65)$ & $504(66.93)$ & \\
\hline
\end{tabular}

Abbreviations: MPAI, Mobile Phone Addiction Index; SD, standard deviation; NLAQ, Nutritional Literacy Assessment Questionnaire; BMI, Body Mass Index; CB, carbonated beverages; OSBB, other sugar-based beverages; MET, Metabolic Equivalent.

Table 2. Multivariate logistic model to explore MPAI and other potential factors that may influence carbonated beverages intake stratified by sex.

\begin{tabular}{|c|c|c|}
\hline Characteristics & $\begin{array}{c}\text { Male } \\
\text { Adjusted OR (95\%CI) }\end{array}$ & $\begin{array}{c}\text { Female } \\
\text { Adjusted OR }(95 \% \mathrm{CI})\end{array}$ \\
\hline MPAI (score) & $1.023(1.004-1.042)$ * & $1.026(1.013-1.039) *$ \\
\hline Age (years) & $0.979(0.915-1.048)$ & $0.958(0.916-1.003)$ \\
\hline \multicolumn{3}{|l|}{ NLAQ (score) } \\
\hline Acquisition capacity & $0.954(0.893-1.020)$ & $1.045(0.999-1.094)$ \\
\hline Comprehension capacity & $1.015(0.952-1.081)$ & $1.039(0.993-1.088)$ \\
\hline Application capacity & $1.007(0.911-1.112)$ & $1.012(0.942-1.089)$ \\
\hline \multicolumn{3}{|l|}{$\operatorname{BMI}\left(\mathrm{kg} / \mathrm{m}^{2}\right)$} \\
\hline Normal & 1 (Reference) & 1 (Reference) \\
\hline Underweight & $0.850(0.292-2.474)$ & $1.144(0.798-1.641)$ \\
\hline Overweight and obese & $1.149(0.702-1.880)$ & $1.495(0.807-2.773)$ \\
\hline \multicolumn{3}{|l|}{ Total physical activity (MET/min/w) } \\
\hline$<600 \mathrm{MET} / \mathrm{min} / \mathrm{w}$ & 1 (Reference) & 1 (Reference) \\
\hline 600-4000 MET/min/w & $0.880(0.427-1.815)$ & $0.956(0.679-1.348)$ \\
\hline$\geq 4000 \mathrm{MET} / \mathrm{min} / \mathrm{w}$ & $0.771(0.291-2.046)$ & $0.687(0.285-1.652)$ \\
\hline \multicolumn{3}{|l|}{ Total expenditure (CNY / month) } \\
\hline$<2000 \mathrm{CNY} /$ month & 1 (Reference) & 1 (Reference) \\
\hline$>2000 \mathrm{CNY} /$ month & $0.868(0.516-1.463)$ & $1.308(0.912-1.875)$ \\
\hline \multicolumn{3}{|l|}{ Food expenditure (CNY / month) } \\
\hline$<1000 \mathrm{CNY} / \mathrm{month}$ & 1 (Reference) & 1 (Reference) \\
\hline$\geq 1000 \mathrm{CNY} /$ month & $1.881(1.078-3.281) *$ & $1.092(0.756-1.577)$ \\
\hline
\end{tabular}

Abbreviations: MPAI, Mobile Phone Addiction Index; OR, odds ratio; CI, confidence interval; NLAQ, Nutritional Literacy Assessment Questionnaire; BMI, Body Mass Index; MET, Metabolic Equivalent. * $p<0.05$. 
Table 3. Multivariate logistic model to explore MPAI and other potential factors that may influence other sugar-based beverages intake stratified by sex.

\begin{tabular}{|c|c|c|}
\hline Characteristics & $\begin{array}{c}\text { Male } \\
\text { Adjusted OR (95\%CI) }\end{array}$ & $\begin{array}{c}\text { Female } \\
\text { Adjusted OR }(95 \% \mathrm{CI})\end{array}$ \\
\hline MPAI (score) & $1.019(1.001-1.038)$ * & $1.020(1.007-1.033) *$ \\
\hline Age (years) & $0.929(0.865-0.997) *$ & $0.948(0.904-0.993) *$ \\
\hline \multicolumn{3}{|l|}{ NLAQ (score) } \\
\hline Acquisition capacity & $1.023(0.957-1.093)$ & $1.034(0.987-1.082)$ \\
\hline Comprehension capacity & $1.054(0.989-1.123)$ & $1.010(0.965-1.057)$ \\
\hline Application capacity & $0.994(0.900-1.098)$ & $0.978(0.910-1.052)$ \\
\hline \multicolumn{3}{|l|}{$\mathrm{BMI}\left(\mathrm{kg} / \mathrm{m}^{2}\right)$} \\
\hline Normal & 1 (Reference) & 1 (Reference) \\
\hline Underweight & $0.631(0.220-1.815)$ & $1.081(0.750-1.557)$ \\
\hline Overweight and obese & $0.830(0.511-1.349)$ & $1.687(0.893-3.187)$ \\
\hline \multicolumn{3}{|l|}{ Total physical activity (MET/min/w) } \\
\hline$<600 \mathrm{MET} / \mathrm{min} / \mathrm{w}$ & 1 (Reference) & 1 (Reference) \\
\hline 600-4000 MET/min/w & $0.716(0.353-1.454)$ & $0.763(0.540-1.080)$ \\
\hline$\geq 4000 \mathrm{MET} / \mathrm{min} / \mathrm{w}$ & $0.859(0.331-2.226)$ & $0.448(0.185-1.088)$ \\
\hline \multicolumn{3}{|l|}{ Total expenditure (CNY / month) } \\
\hline$<2000 \mathrm{CNY} /$ month & 1 (Reference) & 1 (Reference) \\
\hline$\geq 2000 \mathrm{CNY} /$ month & $1.750(1.060-2.890)$ * & $1.991(1.387-2.857)$ * \\
\hline \multicolumn{3}{|l|}{ Food expenditure (CNY / month) } \\
\hline$<1000 \mathrm{CNY} / \mathrm{month}$ & 1 (Reference) & 1 (Reference) \\
\hline$\geq 1000 \mathrm{CNY} /$ month & $2.441(1.378-4.324) *$ & $1.598(1.106-2.309) *$ \\
\hline
\end{tabular}

Abbreviations: MPAI, Mobile Phone Addiction Index; OR, odds ratio; CI, confidence interval; NLAQ, Nutritional Literacy Assessment Questionnaire; BMI, Body Mass Index; MET, Metabolic Equivalent. ${ }^{*} p<0.05$.

Table 4. Multivariate logistic model to explore MPAI and other potential factors that may influence sugar/chocolate intake stratified by sex.

\begin{tabular}{|c|c|c|}
\hline Characteristics & $\begin{array}{c}\text { Male } \\
\text { Adjusted OR (95\%CI) }\end{array}$ & $\begin{array}{c}\text { Female } \\
\text { Adjusted OR }(95 \% \mathrm{CI})\end{array}$ \\
\hline MPAI (score) & $1.005(0.986-1.025)$ & $1.019(1.006-1.032) *$ \\
\hline Age (years) & $0.942(0.872-1.017)$ & $0.948(0.906-0.993) *$ \\
\hline \multicolumn{3}{|l|}{ NLAQ (score) } \\
\hline Acquisition capacity & $0.996(0.931-1.067)$ & $1.012(0.967-1.059)$ \\
\hline Comprehension capacity & $1.082(1.013-1.155)$ * & $1.035(0.989-1.083)$ \\
\hline Application capacity & $0.901(0.813-0.998) *$ & $0.909(0.846-0.977) *$ \\
\hline \multicolumn{3}{|l|}{ BMI $\left(\mathrm{kg} / \mathrm{m}^{2}\right)$} \\
\hline Normal & 1 (Reference) & 1 (Reference) \\
\hline Underweight & $1.006(0.346-2.927)$ & $1.377(0.963-1.967)$ \\
\hline Overweight and obese & $0.716(0.430-1.192)$ & $0.799(0.421-1.516)$ \\
\hline \multicolumn{3}{|l|}{ Total physical activity (MET/min/w) } \\
\hline$<600 \mathrm{MET} / \mathrm{min} / \mathrm{w}$ & 1 (Reference) & 1 (Reference) \\
\hline 600-4000 MET/min/w & $1.595(0.728-3.493)$ & $1.026(0.728-1.448)$ \\
\hline$\geq 4000 \mathrm{MET} / \mathrm{min} / \mathrm{w}$ & $2.860(1.047-7.812)^{*}$ & $0.798(0.336-1.895)$ \\
\hline \multicolumn{3}{|l|}{ Total expenditure (CNY / month) } \\
\hline$<2000 \mathrm{CNY} /$ month & 1 (Reference) & 1 (Reference) \\
\hline$\geq 2000 \mathrm{CNY} /$ month & $1.042(0.622-1.748)$ & $1.206(0.842-1.727)$ \\
\hline \multicolumn{3}{|l|}{ Food expenditure (CNY/month) } \\
\hline$<1000 \mathrm{CNY} /$ month & 1 (Reference) & 1 (Reference) \\
\hline$\geq 1000 \mathrm{CNY} /$ month & $1.648(0.915-2.967)$ & $0.846(0.587-1.219)$ \\
\hline
\end{tabular}

Abbreviations: MPAI, Mobile Phone Addiction Index; OR, odds ratio; CI, confidence interval; NLAQ, Nutritional Literacy Assessment Questionnaire; BMI, Body Mass Index; MET, Metabolic Equivalent. ${ }^{*} p<0.05$.

\section{Discussion}

To the best of our knowledge, this study is the first to characterize the current pattern of SSF consumption in medical college students according to sex and to explore the association between the MPAI and SSF intake in students from Shanghai, China. To date, most studies have addressed these issues in children or adolescents, but few have focused on college students [36,37]. Compared with children and adolescents, college students may consume higher SSF because of their characteristic independence and immaturity. Yet, little data related to college students have been available, and this topic has needed more attention. In summary, even among medical college students with relatively high nutrition health literacy, the intake of SSF is still not optimistic. The mean intakes of CB, OSBB, and sugar/chocolate were, respectively, $65.66 \mathrm{~mL} / \mathrm{d}, 74.20 \mathrm{~mL} / \mathrm{d}$, and $4.96 \mathrm{~g} / \mathrm{d}$ 
in male participants, and $30.42 \mathrm{~mL} / \mathrm{d}, 71.48 \mathrm{~mL} / \mathrm{d}$, and $4.99 \mathrm{~g} / \mathrm{d}$ in female participants. The male students consumed significantly higher amounts of $C B$, whereas the female students consumed higher amounts of sugar/chocolate. Analysis by multivariable logistic regression showed an obvious association between the MPAI and SSF intake.

With the popularity of Internet, mobile phones, as the most popular mobile Internet terminal, have become essential for human interaction, lifestyle, and access to media [38]. In China, the number of mobile phone users has reached 847 million and is still growing [38]. Although mobile phones bring convenience, some of their hazards are also becoming increasingly apparent. Soni et al. [39] demonstrated that excessive use of mobile phones can develop into serious sleep and behavior problems, and our research also confirmed this finding. The most important finding of this study was that the MPAI was positively associated with CB and OSBB, regardless of sex, and with sugar/chocolate intake in women. This finding is in keeping with and confirms the results obtained in another study [17]. The use of the MPAI allowed us to evaluate the physical, psychological, and behavioral characteristics of mobile phone users more comprehensively than if we had used the sole amount of time spent on mobile phone as a parameter. There are two possible interpretations of our results. On the one hand, users of various electronic equipment, such as phones and television, might be more exposed to SSF commercials [40,41]. College students who use mobile phones for longer may have more opportunities to buy SSF products, which might increase their SSF intake. On the other hand, as mentioned in the literature, participants of all ages choose SSF products as snacks rather than fruits, when viewing electronic equipment for an extended period of time [42]. Elucidating the mechanisms underlying the association between these behaviors, however, requires further investigation.

Moreover, as a potential factor, age also may influence SSF intake. Generally, with the increase in age, the level of education, experience and knowledge will increase accordingly, and people will become more mature and care about their health, thus decreasing their intake of SSF. Consistent with a previous study [43], with age, the intake of OSBB significantly decreased in both sexes, whereas the intake of sugar/chocolate significantly decreased in women only. This finding suggests that age is negatively associated with SSF intake and that SSF intake in women is more susceptible to age than in men. Presumably, with age, the education level and dietary knowledge of college students improve [44]. Women also are more concerned about their appearance than men [45], which causes them to reduce their SSF intake.

Additionally, we found that factors such as the NLAQ, total expenditure, food expenditure, and total physical activity were related to SSF intake. The application capacity of the NLAQ was negatively associated with sugar/chocolate intake in both sexes, which was in line with the results obtained by Buja et al. [46]. However, the comprehension capacity of the NLAQ was positively associated with sugar/chocolate intake in men; this may be explained by research conducted by Prada et al. [47], which indicated that participants with higher education understand the definition of free sugars better but do not necessarily apply this knowledge in practice. This behavior can be assimilated to that of smokers, who know that smoking is harmful to their health but continue to smoke because of the direct pressure exerted by their peers or the social environment [48]. This could explain why the male participants with a higher comprehension capacity had a high intake of sugar/chocolate. Therefore, this study demonstrated that the most important measure to reduce SSF intake in medical college students of different sexes is to improve their capacity to apply dietary health knowledge to their lives.

An unexpected finding was that the progressive increase in total and food expenditure per month further increased the intake of OSBB in both sexes. Based on the result of this study, the mean of total expenditure for this study population was $2160.39 \mathrm{CNY} /$ month. The mean of total expenditure for Chinese college students was about $1700 \mathrm{CNY} /$ month according to a research report published in 2020 [49], and the total expenditure of college students in Shanghai is higher than the national level in China. This study supported 
evidence from previous observations [27] that the participants consumed higher SSF when they had more pocket money in high-consumption areas. College students in highconsumption areas are more likely to buy SSF products when they have more money at their disposal. Furthermore, this study revealed that compared with low physical activity, high physical activity increased the intake of sugar/chocolate in male students. This result aligned with a previous study [28], which demonstrated that boys who spent less time performing moderate and high-intensity physical activity reported lower consumption of sugar-sweetened beverages and sugar than those who spent more time performing moderate and high-intensity physical activity. This result may be explained by the fact that vigorous-intensity exercise consumes a lot of energy [50]. In this context, sugar/chocolates are important sources of fast energy replenishment [51].

\section{Strengths and Limitations}

The present study has several strengths. First, it constituted the first description of the current pattern of SSF consumption and the association between the MPAI and SSF intake according to sex in medical college students from Shanghai, China. Therefore, it provides new evidence for further research on the MPAI and other potential factors that may influence SSF intake in medical college students, which requires more attention. Second, the sample size of this study was relatively large, the research subjects of medicinerelated majors were relatively compliant, and the online questionnaire design included quality control to reduce potential bias. Third, the results of this study provide a scientific basis to reduce SSF consumption among medical college students of different sexes from Shanghai, China, including MPAI, NLAQ, and total and food expenditure.

Some limitations exist in our study. First, the full food-frequency questionnaire was not collected, which would not allow the calculation of the proportion of energy provided by SSF. This is an important issue to be addressed in future research. Second, because the study adopted cross-sectional design, causalities cannot be inferred. The real influence exerted by different factors on SSF intake in medical college students of different sexes is still uncertain. Third, because the study was conducted on a single campus of a university sample originating in Shanghai, and selected college students were all medicine-related majors, the research results cannot be extrapolated to all college students in China. Finally, some other factors that may influence SSF intake were not included in our study, such as the participants' numbers of years attending college; future research needs to take these factors into consideration.

\section{Conclusions}

This study confirmed that SSF intake is widespread among medical college students from Shanghai, China, even if they have relatively high nutrition health literacy. From the public health perspective, SSF consumption should be decreased to prevent various related diseases in medical college students of Shanghai, China. This could be achieved by reducing the MPAI, controlling the total and food expenditure per month in highconsumption areas, and improving application capacity of the NLAQ in universities, family, and other environments. The research object of this study, however, came from only one campus of a university in Shanghai, China, and all students were enrolled in medicinerelated majors. A considerable amount of work is needed to further determine the MPAI and other potential factors that may influence SSF intake by expanding the sample size of college students throughout China, and the causal association between them.

Supplementary Materials: The following are available online at https:/ / www.mdpi.com/article/10 $.3390 /$ nu13072256/s1, Table S1: Factor analysis of Mobile Phone Addiction Index, Table S2: Factor analysis for Nutrition Literacy Assessment Questionnaire. 
Author Contributions: S.L., W.Z. and Y.J. designed the research; W.Z. provided the data; S.L. and J.W. performed the statistical analyses; S.L. and Y.J. wrote the paper; Y.J., G.H., and B.C. reviewed and edited the manuscript; S.L. and Y.J. had primary responsibility for the final content. All authors have read and agreed to the published version of the manuscript.

Funding: This research was funded by the Shanghai Planning Office of Philosophy and Social Science, grant number 2018EGL013.

Institutional Review Board Statement: The study was conducted in accordance with the Declaration of Helsinki, and the protocol was approved by the Ethics Committee of Medical Research, School of Public Health, Fudan University (Protocol code: IRB\#2019-01-0726S; data: 7 January 2019).

Informed Consent Statement: Informed consent was obtained from all subjects involved in the study. Written informed consent has been obtained from the study population to publish this paper.

Data Availability Statement: The data presented in this study are available on request from the corresponding author. The data are not publicly available due to privacy of study participants.

Conflicts of Interest: The authors declare no conflict of interest.

\section{References}

1. Hu, F.B.; Malik, V.S. Sugar-sweetened beverages and risk of obesity and type 2 diabetes: Epidemiologic evidence. Physiol. Behav. 2010, 100, 47-54. [CrossRef]

2. Hu, D.Q.; Cheng, L.X.; Jiang, W.J. Sugar-sweetened beverages consumption and the risk of depression: A meta-analysis of observational studies. J. Affect. Disord. 2019, 245, 348-355. [CrossRef] [PubMed]

3. Beauchamp, G.K. Why do we like sweet taste: A bitter tale? Physiol. Behav. 2016, 164, 432-437. [CrossRef] [PubMed]

4. Anderson, A.; Reid, J.; Thomson, M. Guideline: Sugars Intake for Adults and Children. World Heal. Organ. 2018, 57, 1716-1722.

5. Kit, B.K.; Fakhouri, T.H.I.; Park, S.; Nielsen, S.J.; Ogden, C.L. Trends in sugar-sweetened beverage consumption among youth and adults in the United States: 1999-2010. Am. J. Clin. Nutr. 2013, 98, 180-188. [CrossRef]

6. Brand-Miller, J.C.; Barclay, A.W. Declining consumption of added sugars and sugar-sweetened beverages in Australia: A challenge for obesity prevention. Am. J. Clin. Nutr. 2017, 105, 854-863. [CrossRef] [PubMed]

7. Aburto, T.C.; Pedraza, L.S.; Sanchez-Pimienta, T.G.; Batis, C.; Rivera, J.A. Discretionary Foods Have a High Contribution and Fruit, Vegetables, and Legumes Have a Low Contribution to the Total Energy Intake of the Mexican Population. J. Nutr. 2016, 146, 1881-1887. [CrossRef]

8. Klevay, L.M. Letter by Klevay Regarding Article, “Long-Term Consumption of Sugar-Sweetened and Artificially Sweetened Beverages and Risk of Mortality in US Adults". Circulation 2019, 140, e651. [CrossRef]

9. Park, S.; Onufrak, S.; Sherry, B.; Blanck, H.M. The Relationship between Health-Related Knowledge and Sugar-Sweetened Beverage Intake among US Adults. J. Acad. Nutr. Diet. 2014, 114, 1059-1066. [CrossRef] [PubMed]

10. Stanhope, K.L. Sugar consumption, metabolic disease and obesity: The state of the controversy. Crit. Rev. Clin. Lab. Sci. 2016, 53, 52-67. [CrossRef]

11. Pollock, N.K.; Bundy, V.; Kanto, W.; Davis, C.L.; Bernard, P.J.; Zhu, H.; Gutin, B.; Dong, Y. Greater fructose consumption is associated with cardiometabolic risk markers and visceral adiposity in adolescents. J. Nutr. 2012, 142, 251-257. [CrossRef]

12. Chan, T.F.; Lin, W.T.; Huang, H.L.; Lee, C.Y.; Wu, P.W.; Chiu, Y.W.; Huang, C.C.; Tsai, S.; Lin, C.L.; Lee, C.H. Consumption of Sugar-Sweetened Beverages Is Associated with Components of the Metabolic Syndrome in Adolescents. Nutrients 2014, 6, 2088-2103. [CrossRef] [PubMed]

13. Bhupathiraju, S.N.; Pan, A.; Malik, V.S.; Manson, J.E.; Willett, W.C.; van Dam, R.M.; Hu, F.B. Caffeinated and caffeine-free beverages and risk of type 2 diabetes. Am. J. Clin. Nutr. 2013, 97, 155-166. [CrossRef]

14. de Koning, L.; Malik, V.S.; Kellogg, M.D.; Rimm, E.B.; Willett, W.C.; Hu, F.B. Sweetened Beverage Consumption, Incident Coronary Heart Disease, and Biomarkers of Risk in Men. Circulation 2012, 125, 1735-1741. [CrossRef] [PubMed]

15. Assy, N.; Nasser, G.; Kamayse, I.; Nseir, W.; Beniashvili, Z.; Djibre, A.; Grosovski, M. Soft drink consumption linked with fatty liver in the absence of traditional risk factors. Can. J. Gastroenterol. 2008, 22, 811-816. [CrossRef] [PubMed]

16. Batt, C.; Phipps-Green, A.J.; Black, M.A.; Cadzow, M.; Merriman, M.E.; Topless, R.; Gow, P.; Harrison, A.; Highton, J.; Jones, P.; et al. Sugar-sweetened beverage consumption: A risk factor for prevalent gout with SLC2A9 genotype-specific effects on serum urate and risk of gout. Ann. Rheum. Dis. 2014, 73, 2101-2106. [CrossRef] [PubMed]

17. DeBoer, M.D.; Scharf, R.J.; Demmer, R.T. Sugar-Sweetened Beverages and Weight Gain in 2-to 5-Year-Old Children. Pediatrics 2013, 132, 413-420. [CrossRef]

18. Overby, N.C.; Lillegaard, I.T.L.; Johansson, L.; Andersen, L.F. High intake of added sugar among Norwegian children and adolescents. Public Health Nutr. 2004, 7, 285-293. [CrossRef] [PubMed]

19. Mireku, M.O.; Barker, M.M.; Mutz, J.; Dumontheil, I.; Thomas, M.S.C.; Roosli, M.; Elliott, P.; Toledano, M.B. Night-time screen-based media device use and adolescents' sleep and health-related quality of life. Environ. Int. 2019, 124, 66-78. [CrossRef] 
20. Tebar, W.R.; Christofaro, D.G.D.; Diniz, T.A.; Lofrano-Prado, M.C.; Botero, J.P.; Correia, M.D.; Cucato, G.G.; Ritti-Dias, R.M.; do Prado, W.L. Increased Screen Time Is Associated With Alcohol Desire and Sweetened Foods Consumption During the COVID-19 Pandemic. Front. Nutr. 2021, 8, 630586. [CrossRef] [PubMed]

21. Leung, L. Linking Psychological Attributes to Addiction and Improper Use of the Mobile Phone among Adolescents in Hong Kong. J. Child. Media 2008, 2, 93-113. [CrossRef]

22. Li, J.Y.; Zhan, D.N.; Zhou, Y.H.; Gao, X.M. Loneliness and problematic mobile phone use among adolescents during the COVID-19 pandemic: The roles of escape motivation and self-control. Addict. Behav. 2021, 118, 106857. [CrossRef] [PubMed]

23. Chen, Y.Y.; Zhang, Y.B.; Zhang, L.L.; Luo, F.Z.; Xu, W.T.; Huang, J.H.; Yang, L.Y.; Zhang, W. Childhood emotional neglect and problematic mobile phone use among Chinese adolescents: A longitudinal moderated mediation model involving school engagement and sensation seeking. Child Abuse Negl. 2021, 115, 104991. [CrossRef]

24. Zoellner, J.M.; Hedrick, V.E.; You, W.; Chen, Y.; Davy, B.M.; Porter, K.J.; Bailey, A.; Lane, H.; Alexander, R.; Estabrooks, P.A. Effects of a behavioral and health literacy intervention to reduce sugar-sweetened beverages: A randomized-controlled trial. Int. J. Behav. Nutr. Phys. Act. 2016, 13, 38. [CrossRef] [PubMed]

25. Chen, H.J.; Xue, H.; Kumanyika, S.; Wang, Y. School beverage environment and children's energy expenditure associated with physical education class: An agent-based model simulation. Pediatr. Obes. 2017, 12, 203-212. [CrossRef]

26. Santaliestra-Pasias, A.M.; Dios, J.E.L.; Sprengeler, O.; Hebestreit, A.; De Henauw, S.; Eiben, G.; Felso, R.; Lauria, F.; Tornaritis, M.; Veidebaum, T.; et al. Food and beverage intakes according to physical activity levels in European children: The IDEFICS (Identification and prevention of Dietary and lifestyle induced health EFfects In Children and infantS) study. Public Health Nutr. 2018, 2, 1717-1725. [CrossRef]

27. LaCaille, L.J.; Dauner, K.N.; Krambeer, R.J.; Pedersen, J. Psychosocial and Environmental Determinants of Eating Behaviors, Physical Activity, and Weight Change Among College Students: A Qualitative Analysis. J. Am. Coll. Health 2011, 59, 531-538. [CrossRef] [PubMed]

28. Ogden, C.L.; Kit, B.K.; Carroll, M.D.; Park, S. Consumption of sugar drinks in the United States, 2005-2008. NCHS Data Brief 2011, 71, 1-8.

29. Rosinger, A.; Herrick, K.; Gahche, J.; Park, S. Sugar-sweetened Beverage Consumption Among, U.S. Adults, 2011-2014. NCHS Data Brief 2017, 270, 1-8.

30. Guttersrud, O.; Dalane, J.O.; Pettersen, S. Improving measurement in nutrition literacy research using Rasch modelling: Examining construct validity of stage-specific 'critical nutrition literacy' scales. Public Health Nutr. 2014, 17, 877-883. [CrossRef]

31. Zhang, L.; Jia, Y.N.; Qian, H.H.; Fu, H. Development of assessment indicators system of health literacy for college student in China. Health Educ. Health Promot. 2018, 13, 514-519.

32. Zhu, Y.B. "Obesity paradox"—A phenomenon based upon the health-related outcome on quality of life. Chin. J. Epidemiol. 2013, 34, 294-296.

33. Lee, P.H.; Macfarlane, D.J.; Lam, T.H.; Stewart, S.M. Validity of the International Physical Activity Questionnaire Short Form (IPAQ-SF): A systematic review. Int. J. Behav. Nutr. Phys. Act. 2011, 8, 115. [CrossRef]

34. Ainsworth, B.E.; Haskell, W.L.; Whitt, M.C.; Irwin, M.L.; Swartz, A.M.; Strath, S.J.; O’Brien, W.L.; Bassett, D.R., Jr.; Schmitz, K.H.; Emplaincourt, P.O.; et al. Compendium of physical activities: An update of activity codes and MET intensities. Med. Sci. Sports Exerc. 2000, 32, s498-s504. [CrossRef]

35. Kyu, H.H.; Bachman, V.F.; Alexander, L.T.; Mumford, J.E.; Afshin, A.; Estep, K.; Veerman, J.L.; Delwiche, K.; Iannarone, M.L.; Moyer, M.L.; et al. Physical activity and risk of breast cancer, colon cancer, diabetes, ischemic heart disease, and ischemic stroke events: Systematic review and dose-response meta-analysis for the Global Burden of Disease Study 2013. BMJ 2016, 354, i3857. [CrossRef] [PubMed]

36. Jia, M.; Wang, C.; Zhang, Y.M.; Zheng, Y.D.; Zhang, L.; Huang, Y.J.; Wang, P.Y. Sugary beverage intakes and obesity prevalence among junior high school students in Beijing-A cross-sectional research on SSBs intake. Asia Pac. J. Clin. Nutr. 2012, 21, 425-430.

37. Yang, Q.P.; Xi, Y.; Liu, H.M.; Luo, J.; Ouyang, Y.F.; Sun, M.H.; Yong, C.T.; Xiang, C.H.; Lin, Q. Free Sugars Intake among Chinese Adolescents and Its Association with Dental Caries: A Cross-Sectional Study. Nutrients 2021, 13, 765. [CrossRef] [PubMed]

38. Lian, S.L.; Sun, X.J.; Niu, G.F.; Yang, X.J.; Zhou, Z.K.; Yang, C. Mobile phone addiction and psychological distress among Chinese adolescents: The mediating role of rumination and moderating role of the capacity to be alone. J. Affect. Disord. 2021, 279, 701-710. [CrossRef]

39. Soni, R.; Upadhyay, R.; Jain, M. Prevalence of smart phone addiction, sleep quality and associated behavior problems in adolescents. Int. J. Res. Med. Sci. 2017, 5, 515-519. [CrossRef]

40. Powell, L.M.; Szczypka, G.; Chaloupka, F.J. Trends in Exposure to Television Food Advertisements Among Children and Adolescents in the United States. Arch. Pediatr. Adolesc. Med. 2010, 164, 794-802. [CrossRef] [PubMed]

41. Powell, L.M.; Szczypka, G.; Chaloupka, F.J. Adolescent exposure to food advertising on television. Am. J. Prev. Med. 2007, 33, s251-s256. [CrossRef] [PubMed]

42. Avery, A.; Anderson, C.; McCullough, F. Associations between children's diet quality and watching television during meal or snack consumption: A systematic review. Matern. Child Nutr. 2017, 13, e12428. [CrossRef]

43. Wang, Y.C.; Bleich, S.N.; Gortmaker, S.L. Increasing caloric contribution from sugar-sweetened beverages and $100 \%$ fruit juices among US children and adolescents, 1988-2004. Pediatrics 2008, 121, e1604-e1614. [CrossRef] [PubMed] 
44. Ul Haq, I.; Mariyam, Z.; Li, M.; Huang, X.J.; Jiang, P.; Zeb, F.; Wu, X.Y.; Feng, Q.; Zhou, M. A Comparative Study of Nutritional Status, Knowledge Attitude and Practices (KAP) and Dietary Intake between International and Chinese Students in Nanjing, China. Int. J. Environ. Res. Public Health 2018, 15, 1910. [CrossRef] [PubMed]

45. Gui, Z.H.; Zhu, Y.N.; Cai, L.; Sun, F.H.; Ma, Y.H.; Jing, J.; Chen, Y.J. Sugar-Sweetened Beverage Consumption and Risks of Obesity and Hypertension in Chinese Children and Adolescents: A National Cross-Sectional Analysis. Nutrients 2017, 9, 1302. [CrossRef]

46. Buja, A.; Grotto, G.; Montecchio, L.; De Battisti, E.; Sperotto, M.; Bertoncello, C.; Cocchio, S.; Baldovin, T.; Baldo, V. Association between health literacy and dietary intake of sugar, fat and salt: A systematic review. Public Health Nutr. 2021, 24, 2085-2097. [CrossRef]

47. Prada, M.; Saraiva, M.; Garrido, M.V.; Rodrigues, D.L.; Lopes, D. Knowledge about Sugar Sources and Sugar Intake Guidelines in Portuguese Consumers. Nutrients 2020, 12, 3888. [CrossRef]

48. Vitoria, P.D.; Salgueiro, M.F.; Silva, S.A.; De Vries, H. The impact of social influence on adolescent intention to smoke: Combining types and referents of influence. Br. J. Health Psychol. 2009, 14, 681-699. [CrossRef]

49. Liu, F.R.; Wang, Q.G.; Tian, M.J.; Liu, M.F. Monthly cost of living data analysis of college students. Tech. Wind 2020, 18, 283.

50. Rodriguez, N.R.; Di Marco, N.M.; Langley, S.; American Dietetic Association; Dietitians of Canada; American College of Sports Medicine. American College of Sports Medicine position stand. Nutrition and athletic performance. Med. Sci. Sports Exerc. 2009, 41, 709-731.

51. Wasserman, D.H.; Zinman, B. Exercise in individuals with IDDM. Diabetes Care 1994, 17, 924-937. [CrossRef] [PubMed] 